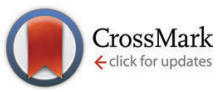

Cite this: Phys. Chem. Chem. Phys., 2015, 17, 15146

Received 3rd February 2015, Accepted 8th May 2015

DOI: $10.1039 / \mathrm{c} 5$ cp00692a

www.rsc.org/pccp

\section{The role of surface oxygenated-species and adsorbed hydrogen in the oxygen reduction reaction (ORR) mechanism and product selectivity on Pd-based catalysts in acid media $\uparrow$}

\author{
R. Rahul, R. K. Singh, B. Bera, R. Devivaraprasad and M. Neergat*
}

\begin{abstract}
Oxygen reduction reaction (ORR) is investigated on bulk $\mathrm{PdO}$-based catalysts (oxides of $\mathrm{Pd}$ and $\mathrm{Pd}_{3} \mathrm{Co}$ ) in oxygen-saturated $0.1 \mathrm{M} \mathrm{HClO}_{4}$ to establish the role of surface oxides and adsorbed hydrogen in the activity and product selectivity $\left(\mathrm{H}_{2} \mathrm{O} / \mathrm{H}_{2} \mathrm{O}_{2}\right)$. The initial voltammetric features suggest that the oxides are inactive toward ORR. The evolution of the ORR voltammograms and potential-dependent $\mathrm{H}_{2} \mathrm{O}_{2}$ generation features on the $\mathrm{PdO}$ catalyst suggest gradual and parallel in situ reduction of the bulk $\mathrm{PdO}$ phase below $\sim 0.4 \mathrm{~V}$ in the hydrogen underpotential deposition $\left(\mathrm{H}_{\text {upd }}\right)$ region; the reduction of the bulk PdO catalyst is confirmed from the X-ray photoelectron spectra (XPS) and X-ray diffraction (XRD) patterns. The potentialdependent $\mathrm{H}_{2} \mathrm{O}_{2}$ generation features originate due to the presence of surface oxides and adsorbed hydrogen; this is further confirmed using halide ions $\left(\mathrm{Cl}^{-}\right.$and $\left.\mathrm{Br}^{-}\right)$and peroxide as the external impurities.
\end{abstract}

\section{Introduction}

Oxygen reduction reaction (ORR) - a complex four-electrontransfer process across an electrode/electrolyte interface - has been investigated for several decades. With the advent of electrochemical energy storage and conversion devices, this reaction has become even more important since it constitutes the electrochemical process at the cathode. ${ }^{1}$ Thus, ORR has been investigated on Pt well-defined single-crystal surfaces and polycrystalline nanoparticles in both acidic and alkaline media. ${ }^{2-4}$ Oxygen gets reduced to water and peroxide as per the most accepted reaction mechanism proposed by Damjanovic et al. ${ }^{5}$ The two-electron reduction of oxygen to $\mathrm{H}_{2} \mathrm{O}_{2}$, parallel to the four-electron reduction to $\mathrm{H}_{2} \mathrm{O}$, in a fuel cell decreases the cell voltage (the reversible redox potential of $\mathrm{H}_{2} \mathrm{O}_{2}$ is $0.7 \mathrm{~V}$ ) because of the mixed potential. Moreover, the $\mathrm{H}_{2} \mathrm{O}_{2}$ that is generated can lead to reduced membrane durability. ${ }^{6,7}$ Therefore, peroxide generation features (using a rotating ring disk electrode (RRDE) technique) with Pt have gained significant attention in the recent years from both fundamental and technological viewpoints. ${ }^{8-14}$ The $\mathrm{H}_{2} \mathrm{O}_{2}$ generation features depend on the active site density of the electrode, catalyst layer thickness and the potential dependent ORR mechanism. ${ }^{13,14}$ Thus, Schneider et al. reported the dependence of $\mathrm{H}_{2} \mathrm{O}_{2}$ formation

Department of Energy Science and Engineering, Indian Institute of Technology Bombay (IITB), Powai, Mumbai, 400076, India. E-mail: nmanoj@iitb.ac.in; Fax: +91 222576 4890; Tel: +91 2225767893

$\dagger$ Electronic supplementary information (ESI) available. See DOI: 10.1039/c5cp00692a on active site density ${ }^{13}$ and Ruvinskiy et al. explained the trend in $\mathrm{H}_{2} \mathrm{O}_{2}$ formation with potential based on the two competing mechanisms of ORR operating parallel to each other. ${ }^{14}$

The ORR activity is highly dependent on the surface cleanliness and it is affected by the adsorbed species or impurities. ${ }^{15-28}$ Effects of cations $\left(\mathrm{Na}^{+}, \mathrm{K}^{+}\right.$, etc. $)$, anions $\left(\mathrm{ClO}_{4}{ }^{-}\right.$, bi-sulphate, etc. $)$ and impurities (halides, phosphates, ammonium, $\mathrm{CO}, \mathrm{SO}_{2}$, $\mathrm{H}_{2} \mathrm{~S}$, etc.) on ORR with platinum single-crystal and nanoparticle surfaces are well-documented in the literature. ${ }^{15-28}$ On precious metals, in the potential range of interest to ORR $(\sim 0.0-1.0 \mathrm{~V})$, the main adsorbates are the oxygenated-species and hydrogen. However, the effect of these in situ generated spectator species $\left(\mathrm{O}_{\text {ads }}\right.$ and $\left.\mathrm{OH}_{\text {ads }}\right)$ and intermediates $\left(\mathrm{O}_{\text {ads }}, \mathrm{OOH}_{\text {ads }}\right.$ and $\left.\mathrm{H}_{2} \mathrm{O}_{2 a d s}\right)$ on ORR activity and product selectivity is not well-understood and only a few reports are available in the literature; Katsounaros et al. used $\mathrm{a}_{2} \mathrm{H}_{2}$ redox reaction to establish the blocking mechanism. ${ }^{29,30}$ Otherwise, there is no way of externally introducing. these species in an electrolyte media to adsorb on a catalyst surface.

Recently, due to the very high cost, stability and overpotential issues with Pt, several new catalyst formulations were investigated as possible alternatives to catalyze ORR. ${ }^{4,31}$ Among them, palladium-based catalysts are the most investigated systems. ${ }^{32-43}$ The electrochemical behavior of Pd in aqueous electrolyte is much more complex when compared to that of Pt, even though both have almost similar voltammetric features. ${ }^{38-40}$ The major differences noticed are the higher hydrogen sorption property and unique oxide formation/reduction behavior. ${ }^{38}$ The formation of pre-monolayer hydrous oxide has a significant role on the electrocatalytic property. ${ }^{38}$ Therefore, Pd presents unique potential-dependent $\mathrm{H}_{2} \mathrm{O}_{2}$ generation 
features parallel to the reduction of oxygen to water. Analysis of these features can provide insight into the role of in situ generated adsorbed species in ORR.

In this manuscript, we report on the use of PdO as a probe surface to investigate the role of surface-oxygenated species on ORR activity and product selectivity $\left(\mathrm{H}_{2} \mathrm{O} / \mathrm{H}_{2} \mathrm{O}_{2}\right)$. Fortunately, bulk Pd oxide reduction is slower than the reduction of oxygen to water and it extends to the hydrogen adsorption $\left(\mathrm{H}_{\mathrm{ads}}\right)$ region. It is confirmed that the unique ORR and peroxide evolution features with Pd is mostly associated with its higher affinity towards oxygen (in the higher potential region) and hydrogen (in the lower potential region). First, the chemical reduction of $\mathrm{PdO}$ in the electrochemical medium is convincingly established. The in situ reduction of bulk oxide along with parallel ORR allows deducing the role of surface oxides and the adsorbed hydrogen on ORR with Pd. The unique peroxide generation features are explained over the entire range of potential (0.0-1.0 V) relevant to ORR.

\section{Experimental}

\subsection{Catalyst synthesis}

Carbon-supported $\mathrm{Pd}$ and $\mathrm{Pd}_{3}$ Co catalysts were synthesized using the procedure reported in the literature. ${ }^{44}$ The as-prepared $\mathrm{Pd}$ and $\mathrm{Pd}_{3}$ Co catalysts were subjected to heat-treatment at $400{ }^{\circ} \mathrm{C}$ for $1 \mathrm{~h}$ in an oxygen-containing atmosphere (5\% oxygen and 95\% argon) to obtain palladium oxide-based catalysts. ${ }^{44} \mathrm{~A}$ brief summary of the catalyst synthesis and physical characterization is given in the ESI. $\dagger$ In the rest of the manuscript, the as-prepared, oxide (heat-treated in oxygen atmosphere), and electrochemically reduced catalysts are denoted as (ASP), (OXD) and (ERD), respectively.

\subsection{Electrochemical characterization}

Catalyst ink and a thin-film electrode were prepared by following the procedure reported in the literature. ${ }^{8,45}$ The details of the catalyst ink and thin-film electrode preparation is mentioned in the ESI. $\dagger$ The electrochemical characterization was performed using a WaveDriver Bipotentiostat (WaveDriver 20, Bipotentiostat/Galvanostat system from Pine Instruments, USA, supported with AfterMath software installed in a Windows 7 operating system). The measurements were conducted in a standard threeelectrode system at room temperature $\left(25^{\circ} \mathrm{C}\right)$ using an $\mathrm{Ag} / \mathrm{AgCl}$ (sat. $\mathrm{KCl}$ ) reference electrode and a Pt wire counter electrode. However, in the manuscript, all potentials are reported against the reversible hydrogen electrode ( $\mathrm{RHE}$ ). The $\mathrm{Ag} / \mathrm{AgCl}$ electrode was calibrated against Pt electrode in $0.1 \mathrm{M} \mathrm{HClO}_{4}$ electrolyte at $25{ }^{\circ} \mathrm{C}$ and the conversion factor (from $\mathrm{Ag} / \mathrm{AgCl}$ to the $\mathrm{RHE}$ potential scale) was $+0.25 \mathrm{~V}$. The ORR voltammograms and peroxide generation features of the oxide catalyst were recorded in an oxygen-saturated $0.1 \mathrm{M} \mathrm{HClO}_{4}$ electrolyte using a RRDE (Pine Instruments, USA) configuration. The electrode disk area was $0.196 \mathrm{~cm}^{2}$ and the ring area was $0.109 \mathrm{~cm}^{2}$. The working electrode was subjected to potential cycling from 1.05 to $0.05 \mathrm{~V}$ at a scan rate of $20 \mathrm{mV} \mathrm{s}^{-1}$ with $1600 \mathrm{rpm}$. The ring potential was held at $1.2 \mathrm{~V}$; the collection efficiency of RRDE was $22 \%{ }^{8}$ To investigate the role of adsorbed impurities, voltammograms were recorded in $0.1 \mathrm{M} \mathrm{HClO}_{4}$ in the presence of $0.1 \mathrm{mM} \mathrm{Cl}^{-}$, $0.1 \mathrm{mM} \mathrm{Br}^{-}$ions and $4 \mathrm{mM} \mathrm{H}_{2} \mathrm{O}_{2}$.

\section{Results and discussion}

Fig. 1a shows the evolution of the ORR voltammograms of Pd (OXD) in oxygen-saturated $0.1 \mathrm{M} \mathrm{HClO}_{4}$ solution. Simultaneously recorded peroxide oxidation current (ring current) is shown in Fig. 1b. For comparison, the ORR voltammogram and the corresponding ring current of the carbon-support (Vulcan $\mathrm{XC}-72$ without $\mathrm{Pd}$ ) is also included. The initial reverse scan with Pd (OXD) (from 1.05 to $0.05 \mathrm{~V}$ ) shows negligible ORR current and ring current down to $\sim 0.4 \mathrm{~V}$; thus, the oxide catalyst is inactive toward ORR. Below $0.4 \mathrm{~V}$, both these currents rise sharply. But, at potential below $\sim 0.15 \mathrm{~V}$, the ring current decreases. In the first forward scan, the half-wave potential of ORR shifts to higher potential $(\sim 0.6 \mathrm{~V})$. The simultaneously recorded ring current decreases with potential up to $0.2 \mathrm{~V}$, increases and reaches a peak maximum at $\sim 0.48 \mathrm{~V}$ and thereafter it decreases with potential till $0.8 \mathrm{~V}$. At higher potentials both currents (ORR and $\mathrm{H}_{2} \mathrm{O}_{2}$ oxidation) are negligible. With

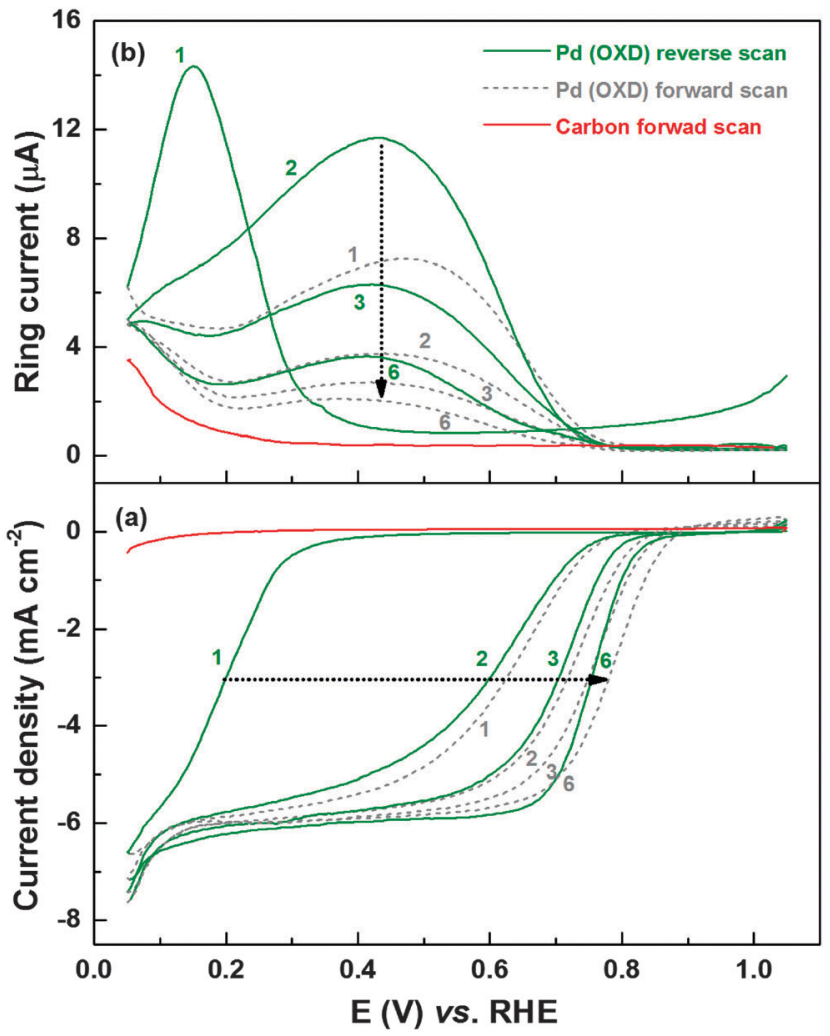

Fig. 1 ORR voltammograms (a) and the corresponding ring current $\left(\mathrm{H}_{2} \mathrm{O}_{2}\right.$ oxidation current) (b) of carbon-supported Pd (OXD) catalyst and the carbon-support recorded in oxygen-saturated $0.1 \mathrm{M} \mathrm{HClO}_{4}$ at a scan rate of $20 \mathrm{mV} \mathrm{s}^{-1}$ with $1600 \mathrm{rpm}$; the electrode potential was held at $0.85 \mathrm{~V} v \mathrm{vs}$. $\mathrm{RHE}$ for $5 \mathrm{~min}$. prior to recording the voltammograms. The numbers 1-6 refer to different scans. The solid and dashed lines refer to reverse (from 1.05 to $0.05 \mathrm{~V}$ ) and forward (from 0.05 to $1.05 \mathrm{~V}$ ) scans, respectively. 
further cycling, the half-wave potential of ORR gradually shifts to higher potentials and almost overlapping voltammograms are obtained by the fifth cycle. Concomitantly, the ring current decreases with cycling and stabilizes gradually. The final stable ORR voltammogram (with the mixed kinetic-diffusion region from 0.7 to $0.9 \mathrm{~V}$ and a well-defined diffusion-limited region below $0.7 \mathrm{~V}$ ) and ring current features resemble that of the as-prepared Pd reported in the literature. ${ }^{46-49}$ The onset of ORR on carbon starts at $\sim 0.2 \mathrm{~V}$ and the ORR activity is negligible when compared to that of the carbon-supported Pd catalyst; but, there is a noticeable ring current at lower potentials. Therefore, the ring current between 0.05-0.2 V with the carbon-supported Pd-based catalysts is the sum of the contributions from carbon and the adsorbed-hydrogen interfering with ORR on $\mathrm{Pd} .^{2,8,9}$

Similar ORR and ring current characteristics are observed with the $\mathrm{Pd}_{3} \mathrm{Co}$ (OXD) as well (Fig. S1, ESI $\dagger$ ). The ring current maxima of $\sim 14 \mu \mathrm{A}$ at $0.1-0.2 \mathrm{~V}$ are comparable with both the oxide catalysts. Thus, from the ORR voltammograms and ring current features, it is clear that the surface oxides greatly influence the ORR and its mechanism.

To understand the above-mentioned evolution of ORR voltammograms and ring current features, CVs of fresh Pd (OXD) catalyst were recorded in argon-saturated $0.1 \mathrm{M} \mathrm{HClO}_{4}$ solution (Fig. 2). These CVs of Pd (OXD) show features different from those of the as-prepared Pd catalyst (Fig. S2, ESI $\dagger$ ). Initially, there is a high reduction current in the hydrogen underpotential deposition $\left(\mathrm{H}_{\mathrm{upd}}\right)$ region, and the typical voltammetric features of the $\mathrm{Pd}$ metal in acid (hydrogen adsorption/desorption $\left(\mathrm{H}_{\text {ads/des }}\right)$, the double layer, and $\mathrm{Pd}$ oxidation/reduction $\left(\mathrm{Pd}_{\mathrm{oxd} / \mathrm{red}}\right)$ regions) are not well-developed. But with cycling, the reduction current in the $\mathrm{H}_{\text {upd }}$ region decreases sharply and $\mathrm{H}_{\text {des }}$ peak builds-up gradually. The complete voltammetric features of metallic Pd are obtained in 6-8 cycles. The explanation for this behavior is reported in the literature and the complete reduction of the bulk oxide phase is caused by the adsorbed/evolved

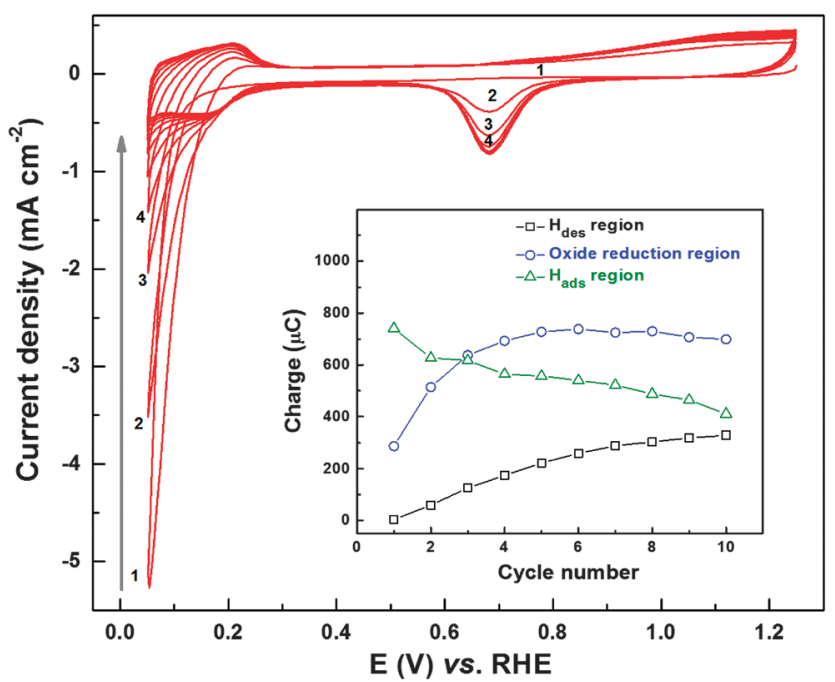

Fig. 2 Initial CVs of $\mathrm{Pd}(\mathrm{OXD})$ recorded in argon-saturated $0.1 \mathrm{M} \mathrm{HClO}_{4}$ at a scan rate of $20 \mathrm{mV} \mathrm{s}^{-1}$. Inset shows the charge estimated from $\mathrm{H}_{\text {des, }}$ oxide reduction, and $\mathrm{H}_{\text {ads }}$ regions with potential cycling. hydrogen at lower potentials in the $\mathrm{H}_{\text {upd }}$ region. Generally, the $\mathrm{Pd} / \mathrm{PdO}$ redox features appear at a potential above $\sim 0.65 \mathrm{~V}$; but with a bulk Pd (OXD) catalyst, the reduction seems to be slow and incomplete in the oxide reduction region. ${ }^{44}$ Recently, similar oxide reduction behavior of graphene oxide with potential cycling is also reported by Kar et al.; the decrease in the reduction charge was attributed to the removal of oxygenated species from the graphene oxide structure. ${ }^{50}$

Inset to Fig. 2 shows the evolution of the charge associated with $\mathrm{H}_{\mathrm{des}}$, oxide reduction, and $\mathrm{H}_{\mathrm{ads}}$ regions during the potential cycling of $\mathrm{Pd}(\mathrm{OXD})$. The charge from the $\mathrm{H}_{\mathrm{des}}$ region increases systematically with cycling and it almost saturates after the eighth cycle. However, the charge from the oxide reduction region $(\sim 0.6-0.9 \mathrm{~V})$ increases in the first three cycles and stabilizes to a constant value $(\sim 700 \mu \mathrm{C})$. On the other hand, the charge from the $\mathrm{H}_{\mathrm{ads}}$ region decreases with cycling. Thus, it can be interpreted that there are two types of reduction processes taking place with the oxide catalysts; one in the $\mathrm{Pd} / \mathrm{PdO}$ redox potential range $(0.6-0.9 \mathrm{~V})$ and another below $\sim 0.4 \mathrm{~V}$ in the $\mathrm{H}_{\text {upd }}$ region.

Similar voltammetric features are also observed with the $\mathrm{Pd}_{3} \mathrm{Co}$ (OXD) catalyst (Fig. S3, ESI $\dagger$ ); the only difference is that the charge (inset to Fig. S3, ESI $\dagger$ ) due to $\mathrm{H}_{\text {ads/des }}$ and $\mathrm{Pd}_{\text {oxd/red }}$ is comparatively higher with $\mathrm{Pd}_{3}$ Co (OXD) than that with $\mathrm{Pd}$ (OXD). From the CV features, it seems that the adsorbed/ absorbed/evolved hydrogen is used for reduction of bulk PdO, which causes a gradual rise in $\mathrm{H}_{\mathrm{des}}$ charge.

For a better understanding of the evolution of CVs and the charges from the three regions $\left(\mathrm{H}_{\mathrm{ads}}, \mathrm{H}_{\mathrm{des}}\right.$ and oxide reduction) on oxide catalysts during electrochemical cycling, the chronoamperometric responses are recorded at different potentials in $0.1 \mathrm{M} \mathrm{HClO}_{4}$ (Fig. 3). From the chronoamperometric responses (Fig. 3a) of $\mathrm{Pd}(\mathrm{OXD})$ and $\mathrm{Pd}_{3} \mathrm{Co}(\mathrm{OXD})$ at $0.45 \mathrm{~V}$ (i.e. outside the $\mathrm{H}_{\text {upd }}$ region of the voltammogram), the reduction charge observed is very low (when compared to that at lower potentials (Fig. $3 \mathrm{~b}$ and $\mathrm{c}$ )). The subsequently recorded CVs are featureless initially resembling those of pure oxide catalysts (Fig. 2 and Fig. S3, ESI $\dagger$ ). This indicates the incomplete reduction of Pd oxide during the chronoamperometric measurements at $0.45 \mathrm{~V}$. The reduction of PdO happens gradually with the subsequent cycling to lower potential $(0.05 \mathrm{~V})$ and the proper voltammetric features of Pd in acid can only be observed after 5-6 cycles (inset to Fig. 3a). The chronoamperometric response recorded at $0.15 \mathrm{~V}$ (Fig. $3 \mathrm{~b}$ ) is broader and intense when compared to that at $0.45 \mathrm{~V}$. Thus, holding the potential at $0.15 \mathrm{~V}$ results in faster reduction of Pd oxide. The subsequently recorded CVs (inset to Fig. 3b) show features similar to that of completely reduced palladium in acid electrolyte. Fig. 3c shows the chronoamperometric responses of $\mathrm{Pd}(\mathrm{OXD})$ and $\mathrm{Pd}_{3} \mathrm{Co}(\mathrm{OXD})$ at $0.05 \mathrm{~V}$. The subsequently recorded CVs (inset to Fig. 3c) are comparable to that of the respective reduced catalyst. Completely developed $\mathrm{H}_{\mathrm{upd}}$, double layer, and $\mathrm{Pd}_{\text {oxd/red }}$ regions are apparent in the CVs of both the catalysts. The sharp and intense chronoamperometric peak at $0.05 \mathrm{~V}$ suggests fast reduction of the PdO phase.

The reduction charge $(8 \mathrm{mC})$, calculated from the chronoamperometric curves, at $0.15 \mathrm{~V}$ is comparable with both $\mathrm{Pd}$ 


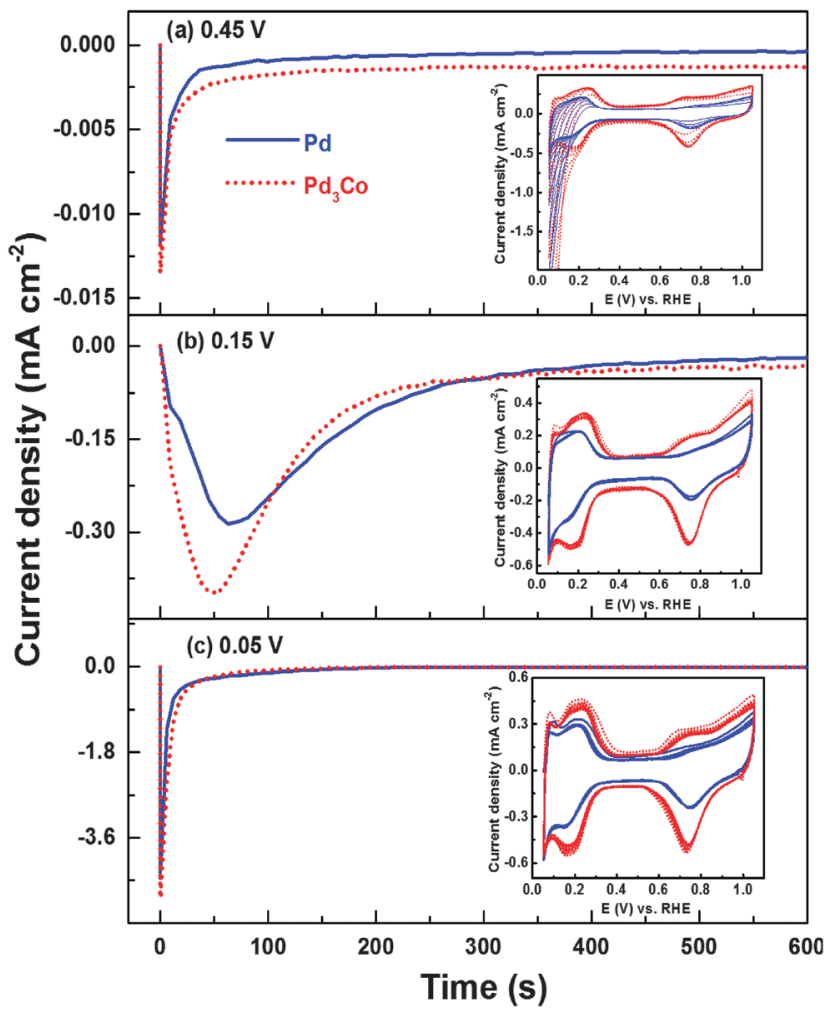

Fig. 3 Chronoamperometric curves of $\mathrm{Pd}(\mathrm{OXD})$ and $\mathrm{Pd}_{3} \mathrm{Co}(\mathrm{OXD})$ catalysts recorded at $0.45 \mathrm{~V}(\mathrm{a}), 0.15 \mathrm{~V}(\mathrm{~b})$, and $0.05 \mathrm{~V}$ (c) in argon-saturated $0.1 \mathrm{M}$ $\mathrm{HClO}_{4}$ electrolyte Insets show the corresponding $\mathrm{CVs}$ recorded immediately after the chronoamperometry experiment.

(OXD) and $\mathrm{Pd}_{3} \mathrm{Co}(\mathrm{OXD})$ catalysts and it almost matches with the estimated charge required to reduce $\mathrm{PdO}(\sim 6 \mathrm{mC}$, assuming $2 \mathrm{e}^{-}$to reduce one PdO, for a typical PdO loading of $\sim 15 \mu \mathrm{g}$ $\mathrm{cm}^{-2}$ on the disk electrode). The reduction charges at $0.05 \mathrm{~V}$ are 11.7 and $12 \mathrm{mC}$ with $\mathrm{Pd}(\mathrm{OXD})$ and $\mathrm{Pd}_{3} \mathrm{Co}$ (OXD), respectively. This is because Pd tends to show a hydrogen evolution reaction (HER) at lower potentials $\mathrm{s}^{51,52}$ and the reduction charge has contributions from both Pd oxide reduction and HER; the latter is not expected at a potential above $0.15 \mathrm{~V}$. The reduction charge calculated from the chronoamperometric peaks at $0.45 \mathrm{~V}(0.36 \mathrm{mC})$ is negligible when compared to that obtained at 0.15 and $0.05 \mathrm{~V}$. Thus, at 0.15 and $0.05 \mathrm{~V}$ complete reduction seems to happen and at $0.45 \mathrm{~V}$ the reduction is negligible. Thus, the initial large cathodic current (Fig. 2 and Fig. S3, ESI $\dagger$ ) and the trends in the charges obtained from the $\mathrm{H}_{\mathrm{des}}, \mathrm{H}_{\mathrm{ads}}$, and oxide reduction regions of the CVs (inset to Fig. 2 and Fig. S3, ESI $\dagger$ ) with both the oxide catalysts are attributed to the absorption/ adsorption/evolution of hydrogen and the subsequent reduction of the bulk oxide in the potential range of $0.05-0.4 \mathrm{~V}^{44}$

To test and establish the extension of oxide reduction to the $\mathrm{H}_{\text {upd }}$ region, CVs of carbon-supported Pd (ASP) were recorded in $0.1 \mathrm{M} \mathrm{HClO}_{4}$ solution from $0.05 \mathrm{~V}$ to different upper potentials $(0.45 \mathrm{~V}$ to $1.65 \mathrm{~V})$ (Fig. 4). The typical precious metal features $\left(\mathrm{H}_{\mathrm{ads} / \mathrm{des}}(0-0.32 \mathrm{~V})\right.$; double layer $(0.32-0.70 \mathrm{~V})$ and $\mathrm{Pd}_{\text {oxd/red }}$ (above $0.7 \mathrm{~V}$ )) can be observed from the CVs. Burke et al. investigated the interaction of Pd with oxygen in acidic

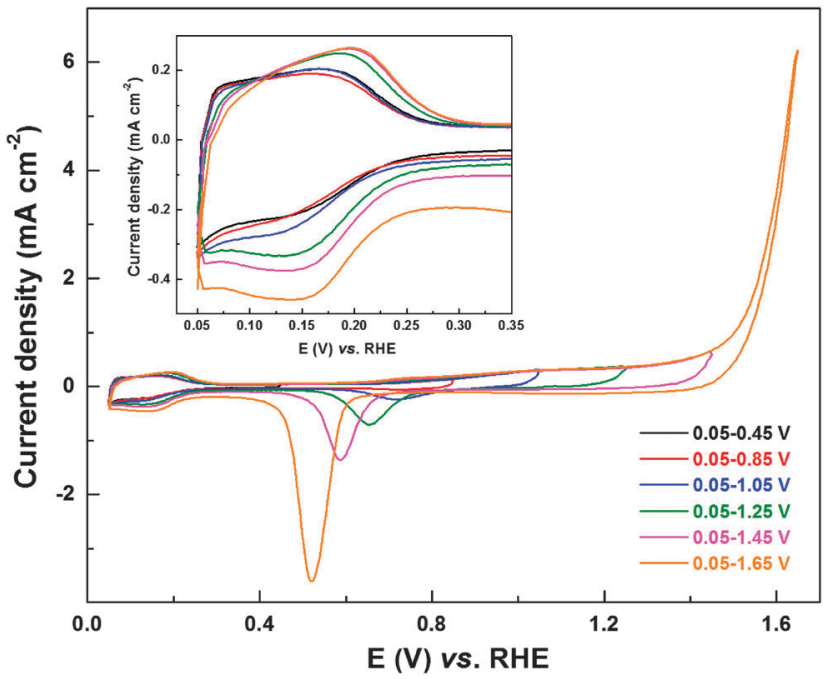

Fig. $4 \mathrm{CVs}$ of carbon-supported Pd (ASP) recorded in argon-saturated $0.1 \mathrm{M} \mathrm{HClO}_{4}$ at a scan rate of $20 \mathrm{mV} \mathrm{s}^{-1}$ with different upper potential limits; inset shows the magnified view of $\mathrm{H}_{\text {upd }}$ region.

and alkaline electrolyte and reported hydrous oxide growth, formation of species with a higher oxidation state $\left(\mathrm{PdO}_{2}\right.$ and $\mathrm{PdO}_{3}$ ) and dissolution during potential cycling. ${ }^{38}$ The formation of pre-monolayer surface hydrous oxide species has a significant role in ORR activity and product selectivity, but, the exact nature and its influence on $\mathrm{H}_{2} \mathrm{O}_{2}$ formation is not well understood. ${ }^{38}$ However, in the case of $\mathrm{PdO}$, the presence of bulk oxide species would significantly enhance the formation of the hydrous oxide and hence its effect is pronounced. The CVs with an upper potential limit of $0.45,0.85$, and $1.05 \mathrm{~V}$ show comparable $\mathrm{H}_{\mathrm{ads}}$ area. With further increase in the upper potential limit (1.25, 1.45 , and $1.65 \mathrm{~V}$ ), the $\mathrm{H}_{\text {ads }}$ area increases (inset to Fig. 4). The oxide formation starts at $\sim 0.7 \mathrm{~V}$, and with increase in the upper potential limit up to $1.3 \mathrm{~V}$, there is a gradual increase in the corresponding current. This plateau in oxide formation region $(1.1-1.3 \mathrm{~V})$ corresponds to a monolayer oxide formation. ${ }^{53,54}$ Further increase in potential results in an exponential rise in oxide formation current. This high current is associated with multilayer oxide formation and the oxygen evolution reaction (OER) occurring on $\mathrm{Pd}^{53,55,56}$ With increase in the upper potential limit of the CVs, there is a corresponding rise in oxide reduction current in the reverse scan and the reduction peak downshifts to lower potentials. ${ }^{38,53,54}$ With multi-layer oxide formation (above $\sim 1.2 \mathrm{~V}$ ), the width of the double layer region (at potential below the oxide reduction peak) increases and it merges with the $\mathrm{H}_{\mathrm{ads}}$ region. Moreover, the $\mathrm{H}_{\mathrm{ads}}$ area increases with the upper potential limit of the $\mathrm{CV}$ on electrodes cycled to potential above $1.2 \mathrm{~V}$. This indicates that the oxide reduction process can extend to lower potentials in the $\mathrm{H}_{\mathrm{ads}}$ region, similar to that observed with $\mathrm{Pd}$ (OXD) and $\mathrm{Pd}_{3} \mathrm{Co}$ (OXD) (Fig. 2 and Fig. S3, ESI†).

To confirm the reduction of oxides, XRD patterns of the samples were recorded after the electrochemical treatment. Fig. 5 shows the XRD patterns of carbon-supported Pd (ASP), Pd (OXD), Pd (ERD) and $\mathrm{Pd}_{3} \mathrm{Co}$ (ERD). The first broad peak at a 


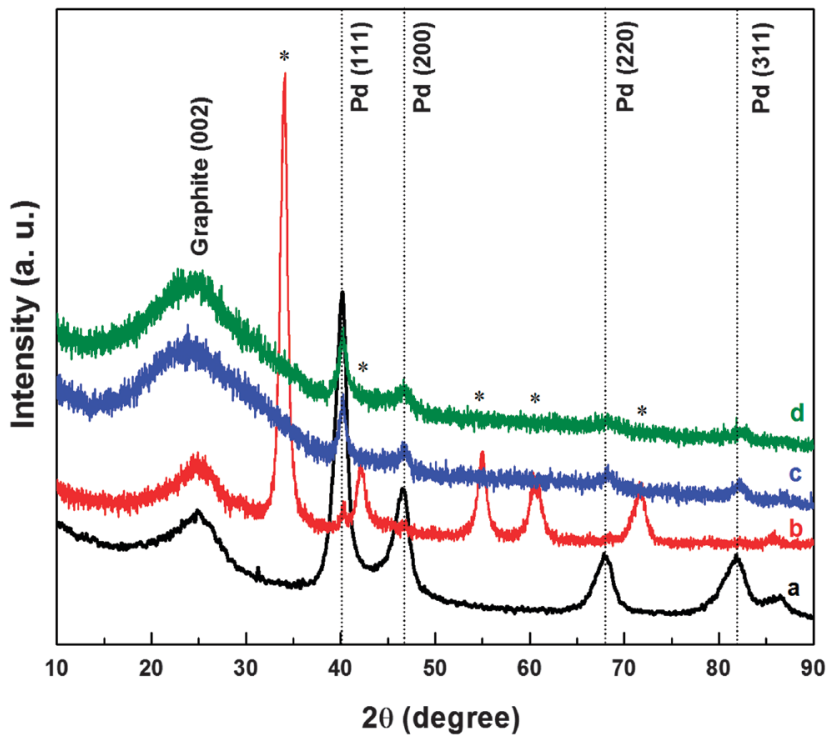

Fig. 5 XRD patterns of $\mathrm{Pd}$ (ASP) (a), $\mathrm{Pd}$ (OXD) (b), $\mathrm{Pd}(\mathrm{ERD})$ (c), and $\mathrm{Pd}_{3} \mathrm{Co}$ (ERD) (d) catalysts. The vertical dotted lines refer to the peak positions of standard Pd (JCPDS file No. 03-065-6174) and the reflections marked with (*) refer to PdO phase (JCPDS file No. 01-075-0584).

$2 \theta$ value of $\sim 25^{\circ}$ in all the $\mathrm{XRD}$ patterns is attributed to the graphite (002) peak of the Vulcan XC-72 carbon-support. The peaks at $40.2^{\circ}, 46.7^{\circ}, 68.3^{\circ}, 82.6^{\circ}$ are consistent with a face centred cubic (fcc) crystal structure of Pd corresponding to the (111), (200), (220), and (311) planes, respectively. The dotted lines indicate peak positions of standard Pd (JCPDS file No. 03-065-6174). The XRD pattern of Pd oxide matches with the standard PdO phase reported in the literature (JCPDS file No. 01-075-0584). The XRD patterns of oxide catalysts after exposure to electrochemical conditions show peaks corresponding to the fcc structure of palladium and those of the oxide phase are not apparent. Thus, it can be inferred that the bulk oxide reduction happens during the electrochemical process.

The reduction of Pd oxide in the electrochemical medium is further confirmed with X-ray photoelectron spectroscopy (XPS). Fig. 6 shows the Pd 3d core-level XPS spectra of carbonsupported Pd (ASP), Pd (OXD) and Pd (ERD) catalysts. The Pd $3 \mathrm{~d}_{5 / 2}$ spin state of the Pd (ASP) catalyst can be deconvoluted into two peaks (Fig. 6a); the deconvolution is performed keeping the Pd 3d spin-orbit coupling constant at $5.2 \mathrm{eV}$. The peak at $\sim 335.6 \mathrm{eV}$ can be assigned to the $\mathrm{Pd}^{0}$ valence state and that at $\sim 336.6 \mathrm{eV}$ to $\mathrm{Pd}^{2+}$ (PdO). Similarly, the Pd $3 \mathrm{~d}_{3 / 2}$ state of $\mathrm{Pd}$ (ASP) is also deconvoluted into two peaks with binding energies of $\sim 340.8 \mathrm{eV}\left(\mathrm{Pd}^{0}\right)$ and $\sim 341.9 \mathrm{eV}\left(\mathrm{Pd}^{2+}\right)$; these values match with those reported for metallic $\mathrm{Pd}$ and $\mathrm{Pd}^{2+}$ in the literature. ${ }^{49,57-59}$ The spectrum of Pd (OXD) is also fitted with two components for each spin state (Fig. 6b). The peak at $\sim 337.1 \mathrm{eV}\left(\operatorname{Pd} 3 \mathrm{~d}_{5 / 2}\right)$ is assigned to photoelectrons from the $\mathrm{PdO}$ phase and that at $\sim 337.8 \mathrm{eV}$ from the $\mathrm{PdO}_{2}$ phase. ${ }^{60}$ The Pd $3 \mathrm{~d}_{3 / 2}$ state of Pd (OXD) at $\sim 342.3$ and $\sim 342.9 \mathrm{eV}$ are assigned to the $\mathrm{PdO}$ and $\mathrm{PdO}_{2}$ phases, respectively.

The Pd 3d peak position of $\mathrm{PdO}\left(\mathrm{Pd}^{2+}\right.$ binding energy) in the Pd (OXD) catalyst is shifted to higher value when compared to that of the Pd (ASP) (a shift of $\sim 0.5 \mathrm{eV}$ with $\mathrm{Pd}^{2+}$ binding energy

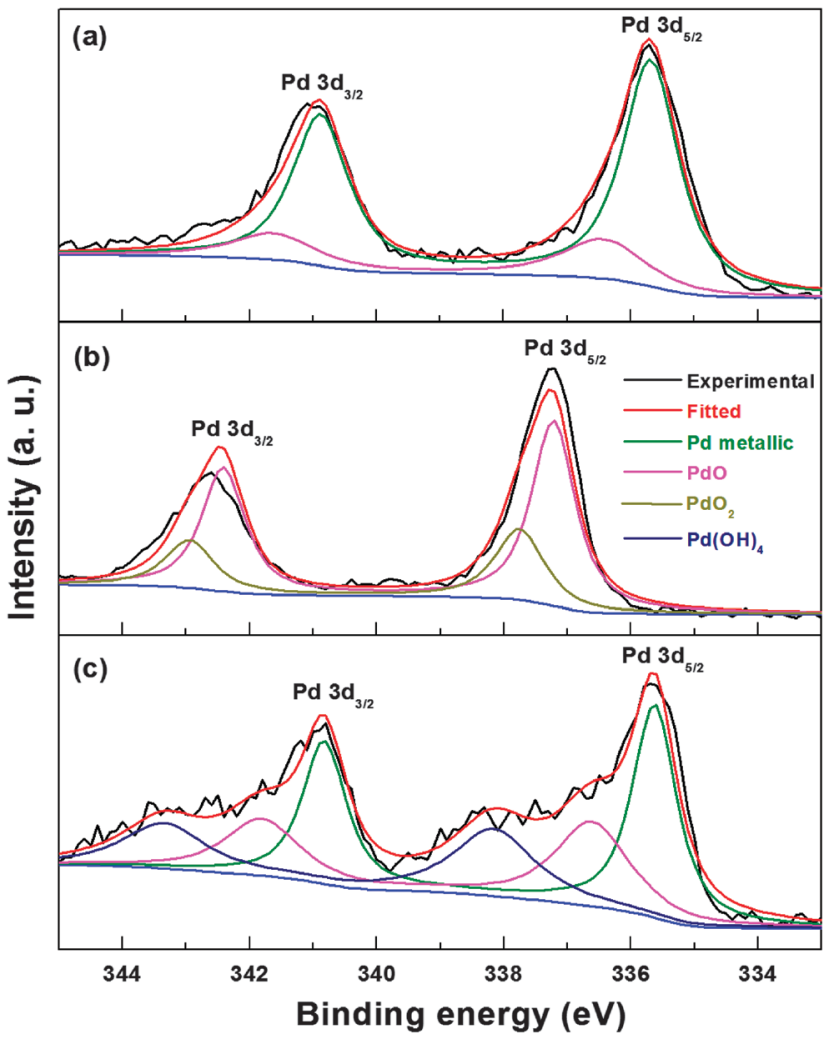

Fig. 6 Pd 3d core-level XPS spectra of carbon-supported Pd (ASP) (a), Pd (OXD) (b), and Pd (ERD) (c).

in $\mathrm{Pd}(\mathrm{OXD})$ with respect to $\mathrm{Pd}^{2+}$ in $\left.\mathrm{Pd}(\mathrm{ASP})\right)$. This upshift in binding energy may be due to the difference in the nature of the PdO phase. The PdO in Pd (ASP) is in the hydrated form at the surface and that in Pd (OXD) is in the anhydrous bulk oxide form. Similar shift in binding energy of the bulk PdO phase relative to surface oxide is reported in the literature. ${ }^{61,62}$ From the XPS spectra, the oxide in Pd (OXD) is in the PdO phase ( $\sim 80 \%$ ) and the remaining is $\mathrm{PdO}_{2}$ phase. The XPS spectrum of Pd (ERD) shows peaks corresponding to metallic Pd with a minor amount of PdO (Fig. 6c). It is reported in the literature that Pd forms a thin oxide layer on the surface at room temperature itself. ${ }^{63}$ Soon after the electrochemical reduction, when the Pd nanoparticles are exposed to atmospheric oxygen, a passive oxygen coverage is formed at the surface. The XPS spectrum of Pd (ERD) shows additional peaks at binding energies of $\sim 338.2 \mathrm{eV}$ $\left(\mathrm{Pd} 3 \mathrm{~d}_{5 / 2}\right)$ and $\sim 343.4 \mathrm{eV}\left(\mathrm{Pd} 3 \mathrm{~d}_{5 / 2}\right)$ which are $\sim 0.4 \mathrm{eV}$ higher than the $\mathrm{PdO}_{2}$ peaks observed in the $\mathrm{Pd}$ (OXD) samples. The binding energy of these additional peaks is attributed to the $\mathrm{Pd}(\mathrm{OH})_{4}$ phase; similar surface hydrated species are reported in the literature. ${ }^{57}$ These hydrated species generated in situ during the potential cycling of oxide catalysts in the electrochemical condition may be similar to that reported by Burke et $a l^{38}$

Fig. S4 (ESI $\dagger$ ) shows the O 1s core-level XPS spectra of Pd (OXD), Pd (ERD) and Pd (ASP). The binding energy of the Pd $3 \mathrm{p}_{3 / 2}$ falls in the range of $\sim 532.5 \mathrm{eV} .^{57,59,62}$ The peak at $\sim 531 \mathrm{eV}$ is attributed to the $\mathrm{O}^{2-}$ bonded to the $\mathrm{Pd}$ atom. The as-prepared sample shows a minor peak at $\sim 531 \mathrm{eV}$ which may be due to the 
surface oxide layer on Pd. With the electrochemically reduced sample, this peak is shifted to higher binding energy $(\sim 531.5 \mathrm{eV})$. The peak at $\sim 534 \mathrm{eV}$ is due to oxygen bonded to the carbonsupport (COO group) and that at $\sim 535.6 \mathrm{eV}$ is assigned to the water molecules adsorbed on the catalyst surface.

From the ORR voltammograms of oxide catalysts it can be inferred that the oxide surface is inactive and a reduced Pd surface is required for catalyzing the ORR. The in situ reduction of PdO happens parallel to the ORR and the surface coverage influences the product selectivity of the reaction; partially covered surface gives rise to higher generation of $\mathrm{H}_{2} \mathrm{O}_{2}$ during ORR. Most of the catalyst surface is reduced during the first reverse scan in the $\mathrm{H}_{\text {upd }}$ region and gradual reduction of the remaining oxides happens with potential cycling. Furthermore, the XPS result shows that along with the in situ reduction of oxide, the $\mathrm{Pd}(\mathrm{OH})_{4}$ phase is also formed on the catalyst surface; this may also contribute to the ORR product selectivity. For a better understanding of the above-mentioned phenomena, ring current features of the as-prepared and electrochemically reduced oxide catalysts (both $\mathrm{Pd}$ and $\mathrm{Pd}_{3} \mathrm{Co}$ ) are compared with that of the well-studied platinum catalyst.

Fig. 7 shows the ring currents with $\mathrm{Pd}$ (ASP) and $\mathrm{Pd}_{3} \mathrm{Co}$ (ASP) catalysts subjected to electrochemical conditioning in oxygen-saturated $0.1 \mathrm{M} \mathrm{HClO}_{4}$; for comparison, ring current features of the as-prepared Pt is also included. On Pt, the ring current characteristics are similar to those reported in the literature. ${ }^{8-10,64-67}$ The peroxide generation features with Pt have been investigated by various groups. The ring current is quite negligible above $0.75 \mathrm{~V}$ and it gradually rises in the potential range of $0.65-0.35 \mathrm{~V}$; and it further increases below $0.35 \mathrm{~V}$. Ruvinskiy et al. explained the ring current trends by the dual path mechanism (the 'series' $2 \mathrm{e}^{-}+2 \mathrm{e}^{-}$reaction mechanism in which the adsorbed hydrogen peroxide $\left(\mathrm{H}_{2} \mathrm{O}_{2 \mathrm{ads}}\right)$ species is a reaction intermediate operating parallel to the 'direct' $4 \mathrm{e}^{-}$reduction of oxygen to water). ${ }^{14}$ At a potential above $\sim 0.75 \mathrm{~V}$, the ORR proceeds preferentially through the $4 \mathrm{e}^{-}$reduction. In the potential range of $0.75-0.35 \mathrm{~V}$, the series mechanism involving the electrochemical reduction of $\mathrm{HO}_{2}$ ads to form $\mathrm{H}_{2} \mathrm{O}_{2}$, a potential-activated step which accelerates towards lower potentials, is operating parallel to the direct dissociation mechanism. ${ }^{14}$ In the potential range of 0.3-0.05 V, as reported by Markovic et al. and Schmidt et al., the rise in the ring current is attributed to active site-blocking by $\mathrm{H}_{\text {upd }} \cdot{ }^{2,8,9}$ However, from Fig. 1, it can be concluded that the carbon also contributes significantly to the ring current in the potential range of $0.05-0.2 \mathrm{~V}$.

The overall ring current features of the other two catalysts (Pd and $\mathrm{Pd}_{3} \mathrm{Co}$ ) are comparable to that of Pt, but the following major differences can be noticed. The highest ring current is observed with $\mathrm{Pd}$ and the ring current at $0.4 \mathrm{~V}$ (in the reverse scan) is in the order of $\mathrm{Pd}$ (ASP) $>\mathrm{Pd}_{3}$ Co (ASP) $>$ Pt. The hysteresis in the ring current of the catalysts is also in the same order. There is a distinguishable ring current maximum at $\sim 0.36 \mathrm{~V}$ and a minimum at $\sim 0.16 \mathrm{~V}$ with Pd-based catalysts. The order of ring current can be explained on the basis of the dependence of peroxide yield on active site density, catalyst layer thickness and adsorbed impurities on the surface. Schneider

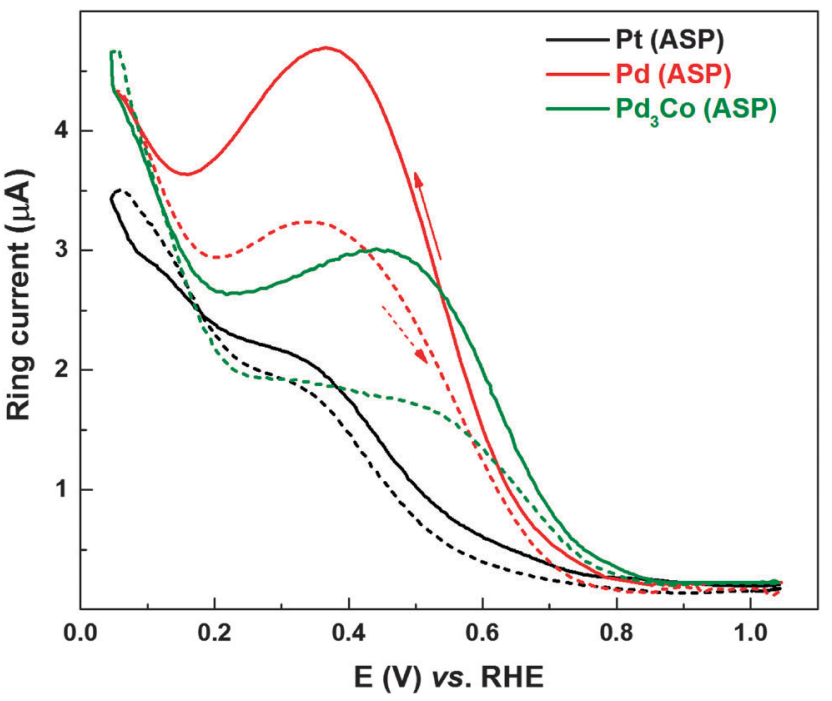

Fig. 7 Ring current of Pt (ASP), Pd (ASP) and $\mathrm{Pd}_{3} \mathrm{Co}(\mathrm{ASP})$ at a scan rate of $20 \mathrm{mV} \mathrm{s}^{-1}$ with $1600 \mathrm{rpm}$ recorded in oxygen-saturated $0.1 \mathrm{M} \mathrm{HClO}_{4}$ electrolyte. The solid and dashed lines refer to reverse (1.05 to $0.05 \mathrm{~V}$ ) and forward (0.05 to $1.05 \mathrm{~V})$ scans, respectively.

et al. reported the effect of active site density and catalyst layer thickness on the peroxide generation features. ${ }^{13}$ The probability of re-adsorption and subsequent reduction of peroxide increases with increase in active site density (catalyst loading/layer thickness), which in turn decreases the escape of $\mathrm{H}_{2} \mathrm{O}_{2}$ from the catalyst layer leading to lower ring current. ${ }^{13} \mathrm{Pd}$ with a $5.1 \mathrm{~nm}$ particle size shows the highest ring current and $\mathrm{Pd}_{3} \mathrm{Co}(2.8 \mathrm{~nm})$ and Pt $(5 \mathrm{~nm})$ show comparable ring currents (see Table S1, ESI $\dagger)$. With same loading $\left(\sim 15 \mu \mathrm{g} \mathrm{cm}^{-2}\right)$ of all the catalysts on the electrode, the active site density of Pd is twice that of Pt (the atomic weight of Pd and Pt is 105 and $195 \mathrm{~g} \mathrm{~mol}^{-1}$, respectively). With $\mathrm{Pd}_{3} \mathrm{Co}(\sim 2.8 \mathrm{~nm})$, the active site density as well as the catalyst layer thickness will be even higher than that of $\mathrm{Pd}$ and Pt. Thus, the higher ring current with Pd in comparison with $\mathrm{Pd}_{3}$ Co can be explained on the basis of lower active site density and catalyst layer thickness. Apart from these effects, the transition metal (Co) may also influence the peroxide generation features by changing the d-band electronic properties and therefore the specific activity of the catalyst. The higher ring current with Pd even with higher active site density and catalyst layer thickness in comparison with $\mathrm{Pt}$, the ring current maxima at $\sim 0.36 \mathrm{~V}$ and minima at $\sim 0.16 \mathrm{~V}$ can be explained by invoking the existence of adsorbed surface impurities on $\mathrm{Pd}$ in the potential range of 0.2-0.7 V. In the case of $\operatorname{Pd}_{3} \mathrm{Co}$, a minor shoulder peak can be observed at a potential of $\sim 0.45 \mathrm{~V}$ and the peak is not that welldefined unlike that with Pd. However, the voltammograms of both $\mathrm{Pd}$ and $\mathrm{Pd}_{3}$ Co (Fig. S2, ESI $\dagger$ ) show a flat double layer region $(\sim 0.6-0.35 \mathrm{~V})$; but, there is a sharper rise in their ring currents compared to that of $\mathrm{Pt}$ in the reverse scan. The ring currents are highest in the $\mathrm{H}_{\text {upd }}$ region; however, there is a sharp peak at $0.36 \mathrm{~V}$ with $\mathrm{Pd}$ and at $0.45 \mathrm{~V}$ with $\mathrm{Pd}_{3}$ Co. Higher ring currents in the $0.30-0.45 \mathrm{~V}$ range on the $\mathrm{Pd}$ catalyst surface $\left(\mathrm{Pt}-\mathrm{H}_{\mathrm{upd}} \approx \mathrm{Pd}-\mathrm{H}_{\text {upd }}<\mathrm{Pd}_{3} \mathrm{Co}-\mathrm{H}_{\text {upd }}\right)$ indicate the additional contribution to the peroxide formation by the surface blocking 
species in the reverse scan in addition to the $\mathrm{H}_{\text {upd }}$. In the reverse scan of $\mathrm{Pd}$, the ring current decreases somewhat below $\sim 0.36 \mathrm{~V}$, reaches a minimum at $\sim 0.16 \mathrm{~V}$, and increases further in the $\mathrm{H}_{\text {upd }}$ region below $\sim 0.16 \mathrm{~V}$. The decrease in ring current (below $0.36 \mathrm{~V}$ in the reverse scan), which is noticeable in the case of $\mathrm{Pd}$ when compared to that of $\mathrm{Pd}_{3} \mathrm{Co}$, is an indication of reduction of the blocking species (perhaps an oxide species or an adsorbed water molecule) in the $\mathrm{H}_{\text {upd }}$ region. It should also be noted that the Pd surface may have intrinsically different activity compared to that of Pt.

Ring current in the reverse scan $(1.05-0.05 \mathrm{~V})$ is significantly higher when compared to that in the forward scan (0.05-1.05 V). The difference between the ring currents in the forward and reverse scans (hysteresis) is more evident in the potential range of $0.2-0.70 \mathrm{~V}$ with Pd-based catalysts, whereas, with Pt the difference is minimal. This is ascribed to the strong hysteresis in the surface oxide formation/reduction with potential. The surface is partially covered by adsorbed-oxygenated species in the reverse scan, and a relatively oxide-free surface is available for oxygen reduction in the forward scan. Thus, blocking by the surface oxide is responsible for higher peroxide formation in the reverse scan. ${ }^{10}$ These oxides may get reduced at lower potentials in the $\mathrm{H}_{\text {upd }}$ region, and the reduced catalyst facilitates complete reduction of oxygen to water as there are lesser blocking species in the forward scan. The ring current features corresponding to the ORR voltammograms (Fig. S5, ESI $\dagger$ ) of Pd (ERD) and $\mathrm{Pd}_{3} \mathrm{Co}(\mathrm{ERD})$ are comparable to that of the as-prepared catalysts discussed above.

Fig. 8 shows the ORR voltammograms and the corresponding ring current responses of Pd (ERD) recorded at different scan rates with $1600 \mathrm{rpm}$. During the reverse scan, in the potential range of $0.2-0.7 \mathrm{~V}$, the ring current maximum (Fig. 8b) decreases with increase in the scan rate and the peak position shifts to lower potentials. Since the change in limiting current below $\sim 0.6 \mathrm{~V}$ is negligible with scan rates, at a given rpm, the amount of $\mathrm{H}_{2} \mathrm{O}_{2}$ generated should be higher at lower scan rates; the $\mathrm{H}_{2} \mathrm{O}_{2}$ formed at the disk electrode gets more time to diffuse to the ring electrode. The shift in ring current maximum to lower potentials at higher scan rates is due to the slow reduction kinetics of the PdO to Pd (see Fig. 4). Thus, from the ring current features of Pd (OXD) and Pd (ERD) catalysts, it can be concluded that the surface oxide formation is the cause of higher peroxide generation in the potential range of 0.2 to $0.7 \mathrm{~V}$. In the forward scan, the potential of the ring current maximum is almost independent of the scan rate for a reduced surface.

For a detailed understanding of peroxide generation characteristics of the Pd catalyst, the disk and ring currents are recorded at different rpms. The ORR limiting current increases with increase in rpm (Fig. S6a, ESI $\dagger$ ) and this is due to the increase in the mass-transfer rate of $\mathrm{O}_{2}$ to the electrode surface and the consequent increase in the reduction of $\mathrm{O}_{2}$ to $\mathrm{H}_{2} \mathrm{O}$ and $\mathrm{H}_{2} \mathrm{O}_{2}$. A corresponding rise in ring current is observed with increase in rpm (Fig. S6b, ESI $\dagger$ ). Other than increase in disk current and consequent ring current with rpm, there are no changes in the features of the ring current. In forward scan, the shift in the ring current maximum to higher potentials with

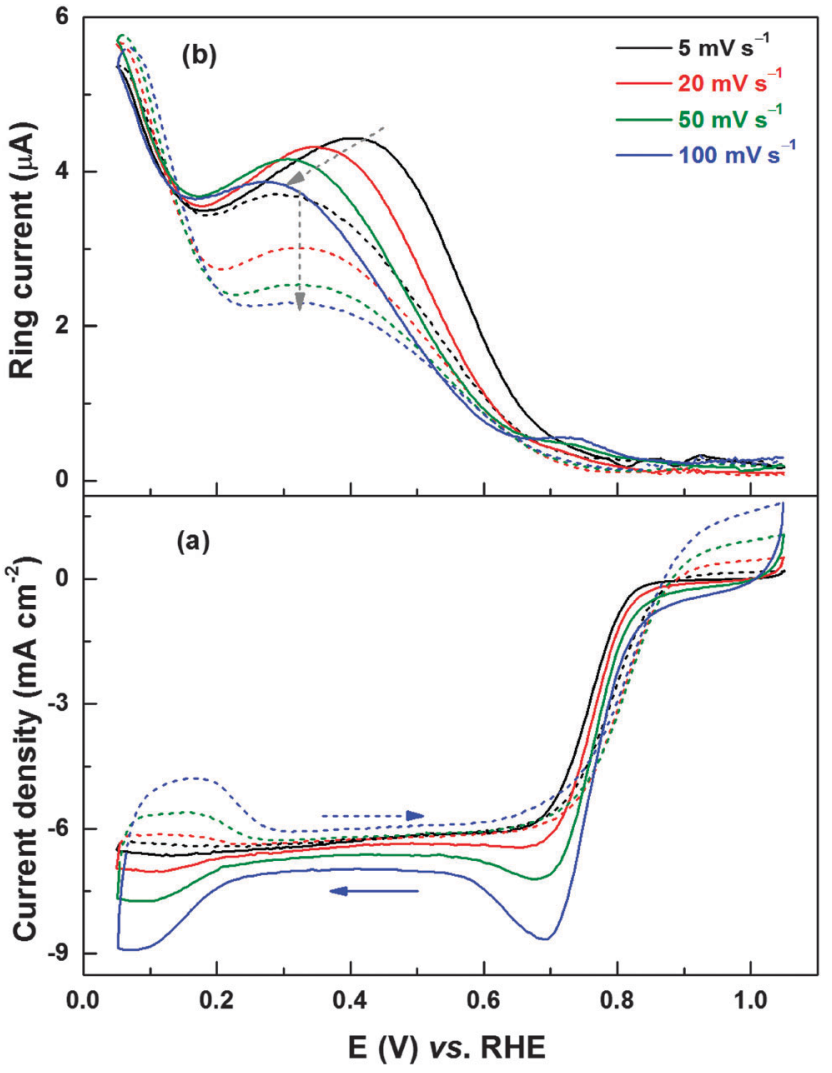

Fig. 8 ORR voltammograms (a) and the corresponding ring current (b) of carbon-supported Pd (ERD) catalyst recorded in oxygen-saturated $0.1 \mathrm{M}$ $\mathrm{HClO}_{4}$ at different scan rates with $1600 \mathrm{rpm}$. The solid and dashed lines refer to reverse $(1.05$ to $0.05 \mathrm{~V})$ and forward $(0.05$ to $1.05 \mathrm{~V})$ scans, respectively.

decrease in rpm is attributed to the lower rate of oxide formation (lower extent of exposure to oxygen at lower rpm).

The electrochemical oxidation/reduction reaction of $\mathrm{H}_{2} \mathrm{O}_{2}$ can give further insight into the role of surface-adsorbed species in the mechanism of ORR. ${ }^{29}$ It can be used as a probe reaction to understand the nature of the surface and the effect of different contaminants. ${ }^{29}$ To establish the role of surface oxide on peroxide generation and the ORR mechanism, peroxide oxidation/reduction is carried out on Pt and Pd-based catalysts. The peroxide ( $4 \mathrm{mM} \mathrm{H}_{2} \mathrm{O}_{2}$ ) oxidation/reduction voltammograms recorded at a scan rate of $20 \mathrm{mV} \mathrm{s}^{-1}$ on Pt in argon-saturated $0.1 \mathrm{M} \mathrm{HClO}_{4}$ and that contaminated with $0.1 \mathrm{mM} \mathrm{KCl}$ and $0.1 \mathrm{mM} \mathrm{KBr}$ are shown in Fig. S7 (ESI†). The hysteresis in the forward and reverse scans is due to the surface oxidation/ reduction that happens parallel to the $\mathrm{H}_{2} \mathrm{O}_{2}$ oxidation/reduction reaction. With the addition of $\mathrm{Cl}^{-}$ions to the electrolyte, the $\mathrm{H}_{2} \mathrm{O}_{2}$ oxidation/reduction characteristics changes considerably. Both the peroxide oxidation and reduction curves deviate from the ideal behavior that is observed with the pure electrolyte. There is no well-defined mass-transport limited region with peroxide reduction; the adsorption of $\mathrm{Cl}^{-}$ions on the Pt surface down-shifts the redox potential by $\sim 17 \mathrm{mV}$. Marked difference is observed with $\mathrm{H}_{2} \mathrm{O}_{2}$ oxidation/reduction characteristics in $\mathrm{Br}^{-}$ ion-contaminated electrolyte. The $\mathrm{H}_{2} \mathrm{O}_{2}$ reduction current decreases 
significantly because of the stronger adsorption of $\mathrm{Br}^{-}$ions on $\mathrm{Pt}$ relative to that of $\mathrm{Cl}^{-}$ions. No mass-transfer-limited region is achieved with $\mathrm{H}_{2} \mathrm{O}_{2}$ reduction with the $\mathrm{Br}^{-}$ion-contaminated electrolyte; the redox potential is shifted to a lower value by $\sim 20 \mathrm{mV}$. The voltammetric features confirm that the strongly adsorbing anions alter the ideal behavior of $\mathrm{H}_{2} \mathrm{O}_{2}$ reduction as well as oxidation. Similar results have been shown by Katsounaros et al. ${ }^{30}$

Fig. 9 shows comparison of $\mathrm{H}_{2} \mathrm{O}_{2}$ oxidation/reduction voltammograms of $\mathrm{Pt} / \mathrm{C}$ and $\mathrm{Pd}$ (ERD) in $0.1 \mathrm{M} \mathrm{HClO}_{4}$ in the presence of $4 \mathrm{mM} \mathrm{H} \mathrm{H}_{2} \mathrm{O}_{2}$; the upper potential limits of the voltammogram with $\mathrm{Pd}$ (ERD) were set at 1.05, 1.25, and $1.45 \mathrm{~V}$. In the reverse scan of $\mathrm{H}_{2} \mathrm{O}_{2}$ reduction, a sharp peak is observed at $\sim 0.62 \mathrm{~V}$ in the voltammogram with an upper potential limit of $1.05 \mathrm{~V}$ and this is due to the Pd oxide reduction. When the potential is taken to higher value (1.25 and $1.45 \mathrm{~V})$, the $\mathrm{Pd}$ reduction peak in the reverse scan becomes intense and it shifts to lower potentials. The difference in the current between forward and reverse scans (hysteresis) in the voltammogram increases with the increase in the upper potential limit. Substantial difference in $\mathrm{H}_{2} \mathrm{O}_{2}$ oxidation/reduction features of the voltammogram can be observed on Pd (ERD) when compared to that of Pt. In the potential region of $\sim 0.76-0.33 \mathrm{~V}$, the $\mathrm{H}_{2} \mathrm{O}_{2}$ reduction features on Pd (ERD) deviates largely from that of Pt. In the forward scan, a slight increase in reduction current is observed up to $0.2 \mathrm{~V}\left(\mathrm{H}_{\mathrm{upd}}\right)$ and this is due to the hydrogen adsorption interfering with the $\mathrm{H}_{2} \mathrm{O}_{2}$ adsorption and subsequent reduction. The $\mathrm{H}_{2} \mathrm{O}_{2}$ reduction current with Pd decreases up to a potential of $\sim 0.6 \mathrm{~V}$, unlike that with Pt. It confirms that the deviation of the voltammetric behavior of the Pd surface from that of $\mathrm{Pt}$ is due to the contamination with adsorbed species.

Fig. 10 shows the $\mathrm{H}_{2} \mathrm{O}_{2}$ oxidation/reduction voltammograms of the Pd (OXD) catalyst. Similar to that observed with ORR voltammogram (Fig. 1), here too, the voltammogram evolves

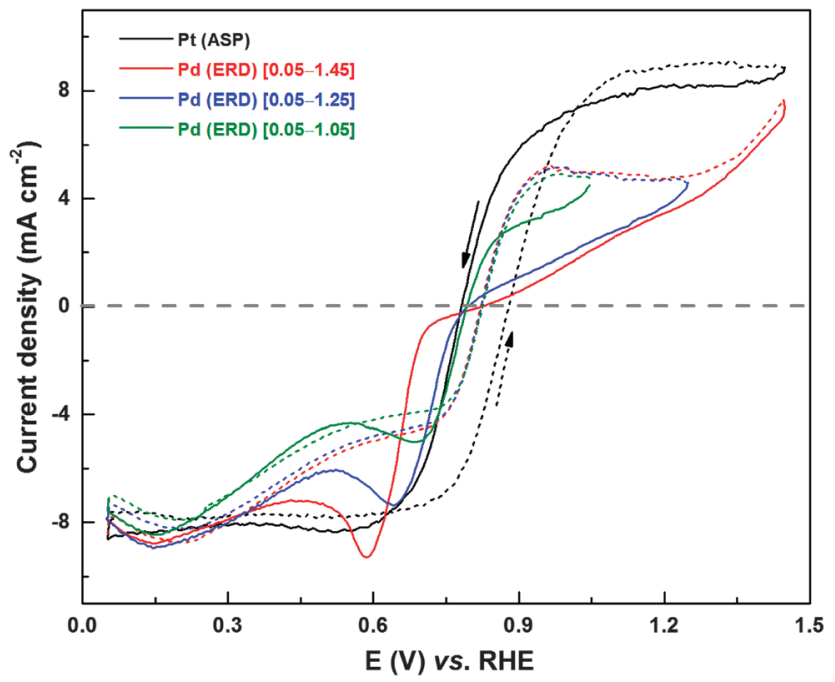

Fig. $9 \mathrm{CVs}$ of Pt (ASP) and Pd (ERD) recorded in argon-saturated $0.1 \mathrm{M}$ $\mathrm{HClO}_{4}$ in the presence of $4 \mathrm{mM} \mathrm{H}_{2} \mathrm{O}_{2}$ at a scan rate of $20 \mathrm{mV} \mathrm{s}^{-1}$ with 1600 rpm. The solid and dashed lines refer to reverse (1.05 to $0.05 \mathrm{~V}$ ) and forward (0.05 to $1.05 \mathrm{~V})$ scans, respectively.

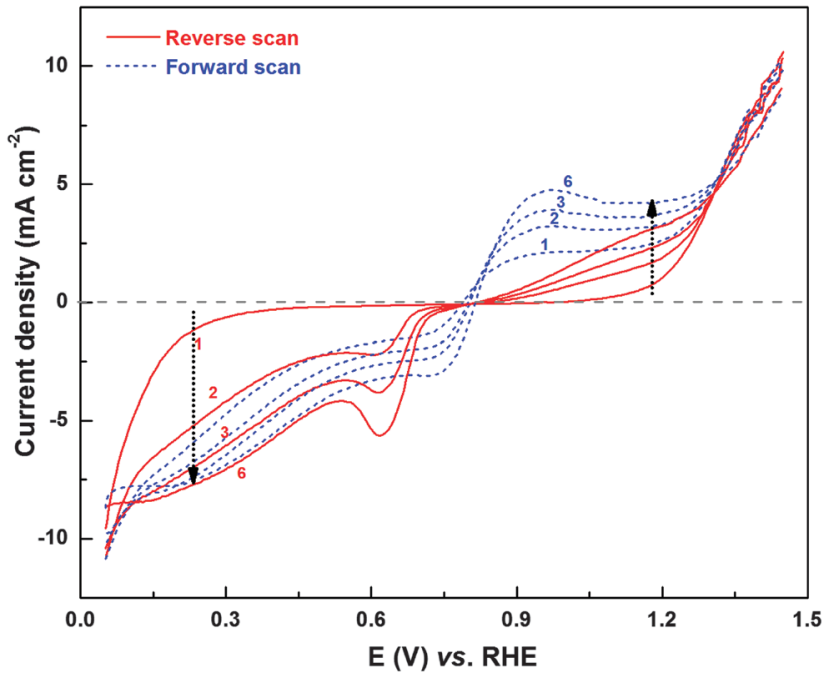

Fig. $10 \mathrm{CVs}$ of $\mathrm{Pd}(\mathrm{OXD})$ recorded in argon-saturated $0.1 \mathrm{M} \mathrm{HClO}_{4}$ in the presence of $4 \mathrm{mM} \mathrm{H}_{2} \mathrm{O}_{2}$ at a scan rate of $20 \mathrm{mV} \mathrm{s}^{-1}$ with $1600 \mathrm{rpm}$. The solid and dashed lines refer to reverse (1.05 to $0.05 \mathrm{~V}$ ) and forward (0.05 to $1.05 \mathrm{~V})$ scans, respectively.

with potential cycling, i.e., with the reduction of PdO. The $\mathrm{H}_{2} \mathrm{O}_{2}$ oxidation and reduction currents increase with cycling and overlapping voltammograms are obtained from the sixth cycle onwards. In the $\mathrm{H}_{2} \mathrm{O}_{2}$ oxidation region, both forward and reverse scans show increase in current with cycling, however, the oxygen evolution (OER) current above $\sim 1.3 \mathrm{~V}$ shows overlapping values. The evolution of $\mathrm{H}_{2} \mathrm{O}_{2}$ oxidation/reduction features further confirms the role of surface oxides and adsorbed-oxygenated species on ORR product selectivity.

\section{Conclusions}

Palladium oxide-based catalysts are used to elucidate the role of surface-adsorbed oxygenated-species and hydrogen on ORR and peroxide generation. Negligible ORR and ring currents in the initial reverse scan (from 1.05 to $0.05 \mathrm{~V}$ ) down to $\sim 0.4 \mathrm{~V}$ suggest that the oxide catalyst is inactive. Upon cycling to the $\mathrm{H}_{\text {upd }}$ region, the oxide catalyst gets reduced. Half-wave potential of ORR shifts to a higher value and the ring current decreases due to gradual reduction of the oxide. The reduction of the bulk oxide to the Pd phase is slow enough to observe the trends in the ORR and ring current features with cycling. The reduction of the PdO phase is confirmed using chronoamperometry, voltammetry, XRD patterns and XPS. A maximum in the ring current at $\sim 0.36 \mathrm{~V}$ and a subsequent minimum at $\sim 0.16 \mathrm{~V}$ are attributed to the formation and removal of hydrated oxygenated species on Pd; the presence of this species is confirmed with XPS spectra. The scan rate dependent ring current features (shift in peroxide maxima) further support this conjecture. Increase in the ring current at a potential below $0.2 \mathrm{~V}$ in the reverse scan is due to contributions from the $\mathrm{H}_{\text {ads }}$ and the carbon-support. Marked difference in the ring current features, observed in the forward and reverse scans, is attributed to the hysteresis in surface oxide formation/reduction during the 
potential cycling. The hysteresis in ring current features and the rise in ring current from $0.2 \mathrm{~V}$ in the forward scan suggest that Pd oxidation starts from the $\mathrm{H}_{\mathrm{upd}}$ region. The order of ring current features of $\mathrm{Pd}, \mathrm{Pd}_{3} \mathrm{Co}$ and $\mathrm{Pt}$ can be explained by the active site density and catalyst layer thickness. The $\mathrm{H}_{2} \mathrm{O}_{2}$ reduction/oxidation voltammogram (with $4 \mathrm{mM} \mathrm{H}_{2} \mathrm{O}_{2}$ ) recorded on Pd deviates from the diffusion-limited ideal behavior observed with $\mathrm{Pt}$ and the features on Pd resemble that of the halide ion-contaminated $\left(\mathrm{Cl}^{-}\right.$or $\mathrm{Br}^{-}$ions) $\mathrm{Pt}$ surface. From these observations, it is clear that the surface of $\mathrm{Pd}$ is contaminated with a passive layer of oxide from the double-layer region itself and it influences the $\mathrm{H}_{2} \mathrm{O}_{2}$ generation characteristic during ORR to a great extent. The potential-dependent catalyst surface characteristics and changes need to be considered while explaining the reaction mechanism and product selectivity. Thus, it is demonstrated that the potential-dependent peroxide generation features can be used for the efficient in situ characterization of the catalyst surface and the same can be extended to other emerging ORR catalyst candidates. The analysis of these features can lead to a wealth of information on the catalyst surface and it helps design better ORR catalysts.

\section{Acknowledgements}

Department of Science and Technology (DST), India, is acknowledged for financial support of the project through a grant SR/S1/ PC-68/2012. Department of Physics and Department of Metallurgical Engineering and Material Science, both at IITB, are acknowledged for physical characterization of the samples.

\section{References}

1 I. Katsounaros, S. Cherevko, A. R. Zeradjanin and K. J. J. Mayrhofer, Angew. Chem., Int. Ed., 2014, 53, 102-121.

2 N. M. Marković, H. A. Gasteiger and P. N. Ross Jr., J. Phys. Chem., 1995, 99, 3411-3415.

3 M. A. Gómez-Marín, R. Rizo and J. M. Feliu, Catal. Sci. Technol., 2014, 4, 1685-1698.

4 H. A. Gasteiger, S. S. Kocha, B. Sompalli and F. T. Wagner, Appl. Catal., B, 2005, 56, 9-35.

5 A. Damjanovic and V. Brusic, Electrochim. Acta, 1967, 12, 615-628.

6 V. A. Sethuraman, J. W. Weidner, A. T. Haug, M. Pemberton and L. V. Protsailo, Electrochim. Acta, 2009, 54, 5571-5582.

7 J. Qiao, M. Saito, K. Hayamizu and T. Okada, J. Electrochem. Soc., 2006, 153, A967-A974.

8 U. A. Paulus, T. J. Schmidt, H. A. Gasteiger and R. J. Behm, J. Electroanal. Chem., 2001, 495, 134-145.

9 T. J. Schmidt, U. A. Paulus, H. A. Gasteiger, N. Alonso-Vante and R. J. Behm, J. Electrochem. Soc., 2000, 147, 2620-2624.

10 M. Neergat, V. Gunasekar and R. K. Singh, J. Electrochem. Soc., 2011, 158, B1060-B1066.

11 T. J. Schmidt, V. Stamenkovic, P. N. Ross, Jr. and N. M. Markovic, Phys. Chem. Chem. Phys., 2003, 5, 400-406.
12 N. Ramaswamy and S. Mukerjee, J. Phys. Chem. C, 2011, 115, 18015-18026.

13 A. Schneider, L. Colmenares, Y. E. Seidel, Z. Jusys, B. Wickman, B. Kasemo and R. J. Behm, Phys. Chem. Chem. Phys., 2008, 10, 1931-1943.

14 P. S. Ruvinskiy, A. Bonnefont, C. Pham-Huu and E. R. Savinova, Langmuir, 2011, 27, 9018-9027.

15 T. Okada, J. Dale, Y. Ayato, O. D. Asbjørnsen, M. Yuasa and I. Sekine, Langmuir, 1999, 15, 8490-8496.

16 J. Durst, M. Chatenet and F. Maillard, Phys. Chem. Chem. Phys., 2012, 14, 13000-13009.

17 A. L. Ong, D. K. Whelligan, M. L. Fox and J. R. Varcoe, Phys. Chem. Chem. Phys., 2013, 15, 18992-19000.

18 J. Omura, H. Yano, M. Watanabe and H. Uchida, Langmuir, 2011, 27, 6464-6470.

19 J. Omura, H. Yano, D. A. Tryk, M. Watanabe and H. Uchida, Langmuir, 2014, 30, 432-439.

20 D. V. Tripkovic, D. Strmcnik, D. van der Vliet, V. Stamenkovic and N. M. Markovic, Faraday Discuss., 2008, 140, 25-40.

21 V. Stamenkovic, N. M. Markovic and P. N. Ross Jr., J. Electroanal. Chem., 2001, 500, 44-51.

22 T. J. Schmidt, U. A. Paulus, H. A. Gasteiger and R. J. Behm, J. Electroanal. Chem., 2001, 508, 41-47.

23 I. Katsounaros, J. C. Meier and K. J. J. Mayrhofer, Electrochim. Acta, 2013, 110, 790-795.

24 N. M. Marković, H. A. Gasteiger, B. N. Grgur and P. N. Ross, J. Electroanal. Chem., 1999, 467, 157-163.

25 Q. He, X. Yang, W. Chen, S. Mukerjee, B. Koel and S. Chen, Phys. Chem. Chem. Phys., 2010, 12, 12544-12555.

26 R. Halseid, M. Heinen, Z. Jusys and R. J. Behm, J. Power Sources, 2008, 176, 435-443.

27 V. Stamenkovic, B. N. Grgur, P. N. Ross and N. M. Markovic, J. Electrochem. Soc., 2005, 152, A277-A282.

28 B. D. Gould, O. A. Baturina and K. E. Swider-Lyons, J. Power Sources, 2009, 188, 89-95.

29 I. Katsounaros, W. B. Schneider, J. C. Meier, U. Benedikt, P. U. Biedermann, A. A. Auer and K. J. J. Mayrhofer, Phys. Chem. Chem. Phys., 2012, 14, 7384-7391.

30 I. Katsounaros, W. B. Schneider, J. C. Meier, U. Benedikt, P. U. Biedermann, A. Cuesta, A. A. Auer and K. J. J. Mayrhofer, Phys. Chem. Chem. Phys., 2013, 15, 8058-8068.

31 A. Brouzgou, S. Q. Song and P. Tsiakaras, Appl. Catal., B, 2012, 127, 371-388.

32 E. Antolini, Energy Environ. Sci., 2009, 2, 915-931.

33 O. Savadogo, K. Lee, K. Oishi, S. Mitsushima, N. Kamiya and K.-I. Ota, Electrochem. Commun., 2004, 6, 105-109.

34 E. Antolini, ChemPlusChem, 2014, 79, 765-775.

35 N. Alexeyeva, A. Sarapuu, K. Tammeveski, F. J. Vidal-Iglesias, J. Solla-Gullón and J. M. Feliu, Electrochim. Acta, 2011, 56, 6702-6708.

36 K. R. Lee and S. I. Woo, Catal. Today, 2014, 232, 171-174.

37 Y. Liu and C. Xu, ChemSusChem, 2013, 6, 78-84.

38 L. D. Burke and J. K. Casey, J. Electrochem. Soc., 1993, 140, 1284-1291.

39 D. A. J. Rand and R. Woods, J. Electroanal. Chem. Interfacial Electrochem., 1973, 44, 83-89. 
40 L. M. Vracar, D. B. Sepa and A. Damjanovic, J. Electrochem. Soc., 1989, 136, 1973-1977.

41 M. Arenz, V. Stamenkovic, T. J. Schmidt, K. Wandelt, P. N. Ross and N. M. Markovic, Surf. Sci., 2003, 523, 199-209.

42 T. J. Schmidt, N. M. Markovic, V. Stamenkovic and P. N. Ross, Jr., Langmuir, 2002, 18, 6969-6975.

43 C. M. Sánchez-Sánchez and A. J. Bard, Anal. Chem., 2009, 81, 8094-8100.

44 R. Rahul, R. K. Singh and M. Neergat, J. Electroanal. Chem., 2014, 712, 223-229.

45 J. Schmidt, H. A. Gasteiger, G. D. Stäb, P. M. Urban, D. M. KoIb and R. J. Behm, J. Electrochem. Soc., 1998, 145, 2354-2358.

46 H. Erikson, A. Kasikov, C. Johans, K. Kontturi, K. Tammeveski and A. Sarapuu, J. Electroanal. Chem., 2011, 652, 1-7.

47 B. Han and C. Xu, Int. J. Hydrogen Energy, 2014, 39, 18247-18255.

48 C. H. Choi, S. H. Park and S. I. Woo, Phys. Chem. Chem. Phys., 2012, 14, 6842-6848.

49 R. K. Singh, R. Rahul and M. Neergat, Phys. Chem. Chem. Phys., 2013, 15, 13044-13051.

50 T. Kar, R. Devivaraprasad, R. K. Singh, B. Bera and M. Neergat, RSC Adv., 2014, 4, 57781-57790.

51 S. Bastide, C. Zlotea, M. Laurent, M. Latroche and C. CachetVivier, J. Electroanal. Chem., 2013, 706, 33-39.

52 C. Cachet-Vivier, S. Bastide, M. Laurent, C. Zlotea and M. Latroche, Electrochim. Acta, 2012, 83, 133-139.

53 M. Grdeń, M. Łukaszewski, G. Jerkiewicz and A. Czerwiński, Electrochim. Acta, 2008, 53, 7583-7598.
54 L. D. Burke and M. B. C. Roche, J. Electroanal. Chem., 1985, 186, 139-154.

55 V. I. Birss, M. Chan, T. Phan, P. Vanýsek and A. Zhang, J. Chem. Soc., Faraday Trans., 1996, 92, 4041-4047.

56 A. Bolzan, M. E. Martins and A. J. Arvia, J. Electroanal. Chem., 1986, 207, 279-292.

57 T. L. Barr, J. Phys. Chem., 1978, 82, 1801-1810.

58 M. Brun, A. Berthet and J. C. Bertolini, J. Electron. Spectrosc. Relat. Phenom., 1999, 104, 55-60.

59 E. H. Voogt, A. J. M. Mens, O. L. J. Gijzeman and J. W. Geus, Surf. Sci., 1996, 350, 21-31.

60 A. L. Guimarães, L. C. Dieguez and M. Schmal, J. Phys. Chem. B, 2003, 107, 4311-4319.

61 M. Peuckert, J. Phys. Chem., 1985, 89, 2481-2486.

62 G. Ketteler, D. F. Ogletree, H. Bluhm, H. Liu, E. L. D. Hebenstreit and M. Salmeron, J. Am. Chem. Soc., 2005, 127, 18269-18273.

63 G. Macfie, A. Cooper and M. F. Cardosi, Electrochim. Acta, 2011, 56, 8394-8402.

64 A. Racz, P. Bele, C. Cremers and U. Stimming, J. Appl. Electrochem., 2007, 37, 1455-1462.

65 L. Colmenares, Z. Jusys and R. J. Behm, Langmuir, 2006, 22, 10437-10445.

66 R. Devivaraprasad, R. Ramesh, N. Naresh, T. Kar, R. K. Singh and M. Neergat, Langmuir, 2014, 30, 8995-9006.

67 M. Neergat, V. Gunasekar and R. Rahul, J. Electroanal. Chem., 2011, 658, 25-32. 